\title{
Conceptual \& Theoretical Perspectives on Electrical Power and its Impact on Productivity in the Informal Productive Sector
}

\author{
Onawola, M.O. \& Lawal, A.K. PhD \\ Department of Business Administration \\ National Open University of Nigeria \\ Offa Study Centre \\ Offa, Kwara State, Nigeria
}

\begin{abstract}
Considering the importance of electrical power to the operations and productivity of the informal sectors and sub-sectors of the economy in the light of its inadequate suppy and availability, research is warranted into the coping strategies of power dependant informal sector in a recessed economy. This paper assesses the available literature from a conceptual and theoretical perspectives on the subject of productivity and coping strategies of power dependant informal sector in recessed economy in Nigeria. The review focuses on informal productive subsectors as well as the role of informal sector and how power affects their productivity. We discuss how different authors express their view on what is informal sectors, their role to economy, their productivity and how their productivity is affected by power sector. Emphasis are on what power is, their role to sectors, their output and how important is power sector to productivity of informal sectors most especially their role to economy growth of the country and the community in particular.
\end{abstract}

Keywords: Power, informal sector/subsector, growth, economy and coping strategies

Journal Reference Format:

Onawola, M.O. \& Lawal, A.K. (2017): Conceptual \& Theoretical Perspectives on Electrical Power and its Impact on Productivity in the Informal Productive Sector. Humanities, Management, Arts, Education \& the Social Sciences Journal. Vol. 6. No. 4, Pp 86-95. Article DOI: dx.doi.org/10.22624/AIMS/HUMANITIES/V5N1P10

\section{INTRODUCTION}

\subsection{Conceptual Clarification}

There are no generally accepted definitions of informal sectors and no uniform criteria to measure them in terms of capital outlay, number of employees, sales turnover, fixed capital investment, available plant and machinery, market share, level of development and even nomenclature. (Ogechukwu 2011). These differences vary from country to country, industry to industry, school to school and author to author (Tajudeen Yusuf, Francis Sewhenu Dansu 2013). Fapounda (1991) opined that the informal sectors are heterogeneous mix, encompassing a wide variety of economic activities that tend to be ignored in economic activities among others include manufacturing activities, construction trade and commerce and other services as repairing all types of vehicle, radio, television sets, refrigerators, hair dressing, carpentry and iron steel welding and fabricating. Wolfenson (2001) described as an integral component of economic development and a crucial element in the effort to lift countries out of poverty. Informal sector are considered the backbone of economic growth in all countries. They play important role in the community and the country economic growth. The most important tool use by informal sector is electricity, power serves as major tool of operation to sectors, and it is also a major catalyst of operation. It plays a long role in the productivity of informal sector. Nigeria economy is characterised by a large number of informal sector many of whom depend on electricity for production and livelihood; so there is a great link between power sector and other economic sector. Therefore adequate power supply and distribution constituted a central core to economic development issue which cannot be over emphasise. 


\subsection{Informal Sectors and Its Importance}

Informal sector in Nigeria refers to economic activities in all sectors of the economy that are operated outside the purview of government regulations. This sector may be invisible, irregular, parallel, non-structured, underground, subterranean, or residual (Magbagbeola, 1996). Most of the informal sector activities are traditional occupation and method of production. They are largely practice by self-employed or those employing few workers. They also contribute to national development by positively influencing the distribution of income in both functional and nominal terms. Informal sectors are driving force for economic growth, job creation and poverty reduction in developing countries. This sector has been recognised as feeder service to large scales industries. (Fabayo 2009). Activities in the informal sector in Nigeria are difficult to measure they are highly dynamic and contribute substantially to growth of Nigeria economy and personal household income. Some sectors that have contributed so much to National development, enhances job creation, innovation and mostly found to be major sources of technological innovation (Iduu Gloria 2012)

In emphasizing the importance of informal sector Rogers stated and quoted by Dr Mba Okechukwu Agwu and Dr Cletus Izunwanne Emeti in European journal (2014):

* They enhance capacity building as they serve as entrepreneurial Training Avenue.

* They create more employment opportunities per unit of investment because of their labour intensive operations.

* They achieve a much more relative high value added operations because they are propelled by basic economic activities that depend mostly on locally sourced raw materials.

* They provide feeder industry services as they serve as major suppliers of intermediate goods and components to large scale industries as well as major agents for the distribution of final products of such industries.

* They provide opportunities for the development of local skills and technology acquisition through adaptation.

Despite the catalytic role stated above and so many roles of informal sector in economic emancipation of countries, some of their major challenges are:

* Finacial Problems: Proper accessibility to finance is always constraint to informal sector because of stringent conditions by financial houses.

* Managemnt Problems: Lack of trained manpower and management skills also constitute a major hindrance to their survival.

* Inadequate Basic Infrastructure: So many problem of infrastructure constitute the problem of informal sectors such infrastructure such as shortages of water supply, inadequate transport system, lack of electricity or epileptic supply of electricity; which is the major factor discussed in the research work. There are still lots more of challenges faced by informal sector such as poor accounting system, multiple taxation unstable policy environments. As mention earlier power supply is the major discussion in this study and how if affect productivity of informal sector.

\section{POWER SUPPLY, ITS ROLE AND EFFECT ON SECTORS}

Electricity generation in Nigeria started around 1986 in Lagos city, after there are establishment of different generating centres for different part of the country like in the northern part of the country Nigerian Electricity supply company (NESCO) as hydroelectric power station in Jos began operation in 1929, Electricity corporation of Nigeria (ECN) in 1962 with construction of $132 \mathrm{KV}$ which connect Ijora power station to Ibadan power station. Then the Niger Dams (NDA) establish in 1962 and so on. ECN and NDA were merge in 1972 to form NEPA and it was later change to PHCN Power holding corporation of Nigeria was privatised by federal government with successor of 18 companies in 2010, though they have been in existence before and was created to break the monopoly of the power holding companies and paving way for independent power producers. 
Despite its long history its development had been very slow and electricity generation in Nigeria had deteriorated over the years. This is rarely expected given the country's rich endowed in natural resources that could facilitate electricity production (Carlos Pestana Barros, Ade Ibiwoye and Shunsuke Managi)

The Energy sector was the focus of intense development interest during the 1990s as plans for the energy industry Contribution to economic growth in creation of jobs and value by extracting, transforming and distributing energy goods and services throughout the economy. It is widely recognized that substantial expansion in quantity, quality and access to energy infrastructure services, are essential to rapid and sustained economic growth, employment generation, poverty reduction and overall well-being of the population in a country (Mbunwe, Muncho Josephine, 2014). Adeyemo (1979) described electricity as the part of infrastructure which is the basic physical facility upon which all other activities in the system significantly depend on.

Development of economist under scored the need to building electricity, as a key stimulates to development, it has been assented that an analysis of electricity is invariably a part of the study economic development (Ukpong 1980)

The power sector right from inception appeared to be faced with the problems of lack of adequate funding and managerial strategies resulting in the steady decline of the company (Adoghe 2008). The demand for electricity increases while their productivity decreases so it results too many organisation folding up as a result of harsh operating environment and epileptic power supply of electricity or power outage. The country economy has large part of contribution from informal sector many of whom depend on electricity for daily production and daily activities. Thus its affects the productivity and output of power dependant informal sector. Though power sector too faces a lot of challenges that affects their output. The challenges they faced are lack of preventive or routine maintenance of $\mathrm{PHCN}$

* Frequent major breakdown arising with use of outdate equipment.

* Lack of proper funding.

- Lack of maintenance culture.

* Lack of infrastructure.

* Inadequate generation due to operational/ technical problems.

With all the challenges faced by power sector, there is no how efficient and effective power could be supply by the sector. With the results in power outage or epileptic power supply which has hinders production process of the informal sector. In the journal various Head of companies or association lamented on how these have killed almost all the companies not to talk of informal sector. Most companies had to result in alternative power supply like generator and its increases cost of production. A journal published December 2016 by the sun "Epileptic power supply killing Nigeria industries”

The president of the country was quoted that that the poor power situation in the country was no longer a laughing matter. The local manufacturers painted the scenario thus: about 70 per cent rise in cost of operation was recorded as power generation. Which rose to above 4.500 megawalts, suddenly dropped to less than 1.2 megawalts, resulting in load shedding by the power distribution companies. Although by the week of the retreat it has improve to 3.36 megawalts, getting a distribution evenly distributed to the real sector has a task the discos have not fund. According to a report from the Manufacturers Association of Nigeria (MAN), members companies in the past three years spent \#20.8 billion monthly on power generation to run production process. The Manufacturer Association of Nigeria (MAN) President, Frank Jacobs, said the ripple effect of power shortages or constant outages were numerous, ranging from cut down in production, job loss to outright closure or relocation to other countries by industries. He added that companies had to bear so much loss as the outages often occurs when goods are in the middle of production. He said when you are producing and power is taken unannounced, goods in line of production would be destroyed. As a result of this Jacobs said many members of MAN have resorted to generating power privately and completely cut off their operations from the national grid. 
The Director General of the Nigeria employers consultative Association (NECA), Mr Segun Oshinowo, said generating alternative power to run manufacturing sector is expensive and invariably increases the cost of production. Undoubtedly would make the nation's industries less competitive. The Director general Lagos chamber of commerce and industries (LCCI) Mr Muda Yusuf, said members of the chamber, be it multi Nationals or medium small or micro entrepreneur[MSME] have all resorted to alternative source of energy, ranging from gas, diesel or PMS which he said is affecting their cost of operation and overall effectiveness.

Yusuf said though some of the companies still manage to operate in public electricity but noted that they have to revert to diesel to power their generators anytime there is an outage which is said to be more expensive. The president/CEO of Erisco foods limited Chief Eric Vmeofia told daily that the high cost of running manufacturing plants on generator was one of the reasons most local industries had remained uncompetitive and profitable as going concerns. Alternative to power use by the informal sector are the coping strategies employ by the sector. Those alternative employ are use of petrol and diesel to power their generator and this increase the cost of production their by reduce the quantity produce invariably reduce their output level. These force some of the sector out of production, it makes some informal to be less productive. Financial experts says the amount spent on fuel and generators by SME will increase remarkably this year 2016 is clearly the harshest since the 2008 economic meltdown. The rough business climate has forced many companies to close shops while the surviving ones are retrenching workers daily. [The sun 2016 December.

\subsection{Role of Informal Sector to Community}

Kemi olalekan oduntan [2014] establish roles of informal sector to economy as follows:-

$>$ Capacity building: - Informal sector provide a platform for training of indigenous entrepreneurs, which drive the wealth creation process at all levels.

$>$ Employment generation: Informal sector have capacity to generate employment as their mode of operation is of more labour intensive, their labour intensive is much higher than that of large enterprises.

$>$ Promoting growth: - By its nature are such they are involved in primary and secondary economic activities that depend heavily on locally sourced materials.

$>$ Poverty alleviation: - it plays a vital role in reducing poverty and inequality among citizenry. This is not unconnected to the affordable and relatively low capital requirement for its establishment.

$>$ Technological Acquisition: - This sector provides opportunities for the development of local skills and technology acquisition through adaptation.

> Industrial Dispersal: - Informal sector easily located in rural areas because they can survive on rudimentary industrial infrastructure.

Tajudeen Olalekan Yusuf and Francis Sewhenu Dansu [2013]. The role of informal sector to economy is enormous and this are some contribution of it to economic growth:-

$>$ When informal sector are located in rural and they help to improve rural infrastructure and the living standard of people.

$>$ Sound development of informal sector has positive implication for improved standard of living of the people in the community and the country at large. In addition it generates foreign exchange for further development of the economy

$>$ Existence of informal sector has minimized the pressure and dependence on government and large companies by job seekers for salaries employment.

$>$ They provide opportunities for the development of local skills and technological acquisition.

$>$ They serve as catalysts to large enterprise through the supply of raw materials and goods to them. They also engage in the distribution of finished products from such big firms to the final consumers. 


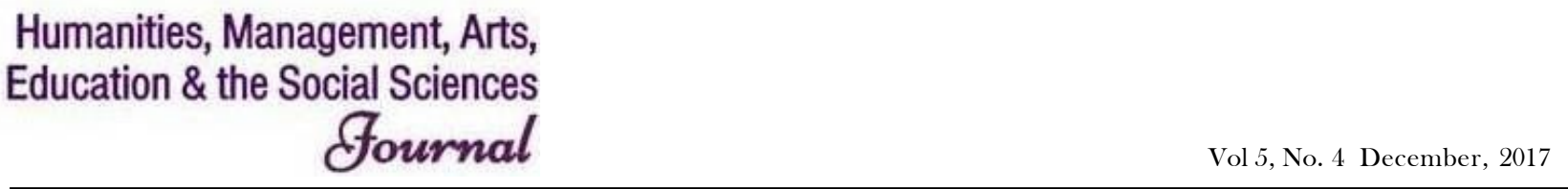

\section{THEORETICAL FRAME WORK}

There are a lot of theories and research carried out on power dependant informal sectors, their productivity in recessed economy. Informal sector is critical in every human society; it is through this that societies and community even the nation can attain any level of development. Volume of theories and research carried out on this topic which is as a result of their relevance. Few that are considered popular are discussed briefly. The theories to be discuss on informal sectors that are in existence in developing countries according to (Yusuff, 2011) include modernization, dependency, neo- liberalism, and structuralism.

\subsection{Theory of Modernization}

This modernization theory saw the informal sector as a remnant of traditional, pre capitalist modes of production and subsistence strategies common to isolated rural peoples. Informal's were trapped outside the modern economy because they lacked the proper education, skills, and value orientations. The language used to describe the growing informal or excess labour includes "marginality," "abnormally swollen," "over distended tertiary sector" and "bazaar types" (Moser (1978) cited in (Yusuff, 2011). In line with this patronizing prescription for national development, the prescription by modernists connotes the idea that urban surpluses would eventually disappear with the rise of industrialization. That capitalist manipulate the reserve army confronting workers in the formal sector with the replacement by cheaper labour in the informal labour market. However, the weakness of modernization theory was that informal sector was not seen as an area of economic growth or dynamism, nor was it characterized as a reservoir of entrepreneurial training and talent. It was seen as a problem to be solved and not a development strategy to be harnessed and promoted.

\subsection{Theory of Dependency}

Hart, 1973, Portes et al, 1981 cited in Yusuff, (2011) t said informal activities were not a mere extension of traditional subsistence strategies and that participants in these unregulated activities were not universally condemned to poverty and marginality. However, other scholars working within the dependency tradition have all too often made the mistake of characterizing informal workers as universally poor and emphasized the sector's supposed marginal position vis-à-vis the modern capitalist sector (Schauffler 1993). Furthermore, in place of developing a systematic definition of what constituted informality, practitioners of the dependency approach (Tokman 1978, 1990, PREALC 1978) often simply described the many common characteristics of enterprises in the sector. Such as: little capital, low technology and production, little profits, utilization of unpaid family labour, easy entry, low efficiency and competition. Furthermore, the dependency approach saw the goal of informal operations as mere survival, not profit maximization. The weakness of dependency theory was that it saw the informal sector arrangement as taking place largely outside of the exploitative formal relations of production. Thus, the informal sector was viewed largely with suspicion as a mere transposition of the rural subsistence sector into the urban environment.

\subsection{Theory of Neo-liberalism}

Neo liberalism is an ideology based on economic liberalism. The ideology favours economic policies that minimize the role of the state and maximize the private business sector (Wikipedia, 2010). Neo Liberalism seeks to transfer control of the economy from public to the private sector under the belief that it will produce a more efficient government and improve the economic health of the nation. Hernando De Soto (1989) asserts that the informal sector is a response to excessive state regulations. He subscribes to the notion that the informal sector is comprised of 'plucky' micro-entrepreneurs who choose to operate informally in order to avoid the costs, time and effort of formal registration. He noted that informal sector would continue to produce informally so long as government procedures are cumbersome and costly in terms bureaucratic red-tapism, lack of property rights, difficult accessibility to productive resources like finance and technology. In his view, unreasonable government rules and regulations are stifling private enterprise. 
De Soto and his followers eagerly champion those who generate income for themselves and their families in the informal sector as the 'real revolutionaries', who heroically stand up to the tyranny of excessive state regulations, and proclaim that these informal workers are the real seeds of the free market (deregulatory) doctrine. De Soto can be credited with turning the informality debate on its head and bringing it out of the academy into public view. He argues that the masses have united in a revolutionary front not as proletarians against capitalist exploitation.

He makes grand claims that the informal sector has the potential not only to create wealth, reduce costs, and democratize politics, but also to push out and replace the first economy. Thus, in comparison to other scholars who see informal economies of growth as exceptional? In the context of global economic crises and restructuring, neoliberal economic ideologies acknowledged the informal economy and encouraged conditionality on aid to developing countries. The essence was to promote formal employment by promulgating state deregulation, free-market development, and curbing social expenditure (Portes 1997). Thus, rather than the informal sector playing its previous supplementary role in the provision of employment and welfare, it is now a primary medium for sustaining the livelihoods of millions of who had been retrenched from their jobs or whose income is not sufficient to support basic needs.

\subsection{Theory of Structuralism}

Structuralisms insist that informality is not simply the result of excess labour supply, or over-regulation. Instead, the central element of the structuralism approach is its insistence that informality is in essence an alternate form of labour utilization (and often exploitation) by capital. Put differently, Maloney (2000) succinctly stated that informal labour relations (like informal workers) are not "just there" by some accident or flaw in capitalist development. Instead, these relations (and workers) are actively "informalized" by capital under the logic of peripheral capitalist accumulation. Arguing along the same line was Rakowski (1994), he argued that the "novelty" of the informal sector is largely illusory. What is new in the production process is not informality, but formal labour related themselves.

The structuralist made two main contributions to the informal sector discourse. First, the informal sector's function according to Castells et al, (1989) is to support capitalist structure, which is supported by globalization, to maintain market competitiveness as producers strive to reduce production costs, especially wages. A critical shortcoming of this theory is that while industrial subcontracting is a central feature of informal sector in developed cities, it is a comparatively insignificant feature of informal sector in developing countries (Aeroe 1992).

\subsection{Theory of electricity or power sector}

According to (Dr Akiri, S. E., Ijuo, Odike Abraham, Apochi and Maria Peace Nov-Dec 2015). This study has attracted some basic theoretical review, reflecting issues bordered on electricity or power and manufacturing productivity growth. Specifically, to consider in this study, the theories include, the liberalized electricity market theory, the traditional theory of cost and modern theory of cost and the Schumpeterian theory of capitalist development. The liberalized electricity or power market theory explains the right of firms to choose to invest in different types of power plants which allow production of electricity at different levels of marginal cost. The theory contends that, since electricity is not storable at reasonable cost, it is optimal for firms to invest in a differentiated portfolio of technologies in order to serve strongly fluctuating demand. Olayemi (2012) cited in (Dr Akiri, S. E., Ijuo, Odike Abraham, Apochi, Maria Peace Nov-Dec 2015) agrees with the adoption of this theory in this work as he cited the experience of some economies that, prior to the liberalization of electricity or power markets, regulated monopolists decided on optimal investment and pricing strategies. The traditional theory of cost admits that the optimal level of output is attainable at a single level of output above which costs began to rise. 
Therefore, the output capacity is fully utilized at a point where the marginal cost curve cuts the average cost curve at the minimum while the former start rising. Under the traditional theory of cost, firms do not build plants with varying productive capacity, thus excess capacity is often a phenomenon experienced by firms. Excess capacity could also mean the difference between the actual output and maximum possible output of a firm, industry, or economy at large, when there are unemployed resources.

However, the modern theory of cost, in its own description, assumed that firms build their plants with some flexibility in their productive capacity and making it possible for such firms to have reserve capacity. The theory also asserts that firms who utilize two-third and three quarters of their adequate supply of power are considered to be efficient. The reserve capacity under the modern theory of cost implies that some outputs can be produced at a single cost. Whichever positions or arguments put forward by each of the theories considered in this study, they are not permanently meant to bridge the gap between the electricity supply and manufacturing productivity growth especially in Nigeria. The permanent solutions should be sought in the total revolution and overhauling of the power sector, to allow the optimal use of the equipment in the manufacturing sector in the country.

For instance, inadequate supply of power makes the manufacturing sectors in Nigeria go for power generator and the cost of running such leads to increase in cost of production such as money spent on petrol, diesel etc. This increase in cost has sent many manufacturing firms out of business and eventually reduces the productivity of the manufacturing sector in the economy (Olayemi, 2012).

The study also adopts the Schumpeterian theory of capitalist development in it contention that innovations and inventions are a major catalyst of economic development; to therefore inform the need of government, NonGovernmental Organizations (NGO), entrepreneurs/owners of manufacturing firms to device possible alternative ways of sourcing energy and of adopting manufacturing machines/equipment that will require little electric power to function in order to reduce the adverse effect of erratic power supply on the productivity of manufacturing firms.

\section{CONCEPTUAL FRAMEWORK}

Informal sector cannot be given a straight or single definition because different people with different definition also its definition differs in countries. Unfortunately it does not have a commonly accepted definition. It has been difficult to evolve a conceptual framework which can be applied to precisely decide whether a particular sector is formal or informal.

Unfortunately, without a precise and unambiguous conceptual framework for demarcating the boundaries between formal and informal sector, systematic research into the salient features of informal sector in ways that will enhance knowledge about this phenomenon may be difficult (Ajakaiye and Akerele, 1996). According to Fapohunda (2012), the conceptualization of the informal economy was initiated by the ILO in 1972 in its report which conceptualized informality as a "way of doing things" epitomized by free entry, low skill, traditional tool usage and labour intensive operation. 
Amin (2002), ILO (2002 \& 2003) and the World Bank (2003) affirm that the informal sector is composed of self-employment that are not regulated and those who work in the informal sector lack social protection. They categorize the informal sector or what is known as the shadow economy in the following ways:

- Self-employment: this consists of unpaid family workers, own account workers and family business owner.

○ Wage workers: including home workers, casual workers, paid domestic workers, temporary workers and non-registered workers.

- Employers: this composed of owners of small scale enterprises.

- For the purpose of this study, 'conceptual framework' the Central Bank of Nigeria (CBN), the Federal Office of Statistics (FOS) now the National Bureau of Statistics (NBS) and the Nigerian Institute of Social and Economic Research (NISER) joined definition of the informal sector will be our operational guide. The three federal government agencies at a jointed workshop in 2001 defined the informal economy as that which operates under unregulated atmosphere and at the same time the government officials are aware of their activities, but they rendered no official returns on their operations. The workshop pigeonholes the conceptualization of the informal economy production units into four classifications, which are:

- Informal production units operating under binding official regulation with autonomous internal regulations;

- Informal production units operating under binding official regulation without internal regulations;

- Informal production units operating without binding official regulations with autonomous internal regulations;

- Informal production units operating without binding official regulation without autonomous regulation (CBN/FOS \& NISER, 2001).

The Dictionary of Modern Economics (1987) defined informal sector as the large volume of self employed in developing countries who are engaged in small scale labour -intensive work. These people are often regarded as unemployed or underemployed. However, the informal sector has been defined in the literature from several dominant perspectives, namely: government regulations, social security, the number of people employed in an enterprise, physical and human capital per worker, mode of operation of the enterprise, source of income, and legal framework. From the perspective of government regulations, Oduh et al (2008) defined an informal sector as one which operates without regulations prescribed by the public authority to govern its organizational behaviour. This definition suggests that informal economic units operate Informal sector are seen as the backbone of the economy and a key source of economic growth, dynamism and flexibility. Other definitions of the informal sector can be found in Feige (1990), Loayza (1997), Henley et al (2006), Schneider (2002), Smith (1994), Bhattacharyya (1999), Hart (1973), and Ajakaiye and Akerele (1996)

A study done by the federal office of statistics shows that $97 \%$ of all business in Nigeria employs than 100 employees, implying that $97 \%$ of all business are informal sectors. These sectors provides, on average $50 \%$ of Nigeria employment. The Nigerian informal sector is the largest and arguably the most dynamic in sub-Saharan Africa. Since the imposition of Nigeria's Structural Adjustment Programme in 1986, informal activity has expanded from an estimated 50 per cent of the urban workforce in the late 1970s to 65 per cent by the late 1980s (Sethuraman, 1981; ILO, 1988) cited in (YUSUFF, Olabisi Sherifat 2011). Severe wage restraint and high rates of retrenchment in the public and private sectors have significantly increased the rates of open and disguised unemployment. In the process, the composition of the under- and unemployed has changed. A growing cadre of unemployed graduates and professionals has begun to swell informal sector statistics. 


\section{CONCLUDING REMARKS}

It is clear that informal sector productivity is affected by power supply, despite informal sector is central and critical in every human society. It is through this sector that societies can attain any level of development and they are said to be secret behind rapid development of countries like Japan, China and Malaysia etc. Low informal sector or entrepreneur is said to be the major causes of under development of most countries in African, Asia, Latin America and the rest. So, informal sector contribute greatly to economy growth and community development.

Literature review shows clearly that power supply is major determinant of productivity in the sector and it plays significant role in the informal sector productivity. It would be a fallacy to conclude that there is no relationship between power consumption and economic growth. Several empirical studies on how to improve informal sector performance, the most common problem affecting informal sector productivity is the power supply or power outages. Thus place of power as a contributor to economic growth cannot be overemphasized. It is therefore paramount that such a sector is not neglected in the country. The government should ensure that power supply is beefed up in diversity so that more economic activity can thrive. Power is the vital backbone of an economy especially to the informal productive sector.

\section{REFERENCES}

1. Ahmadou Aly Mbaye (2014): The Informal Sector, Employment and Structural Transformation.

2. Basil Anthony Ngwu Onugu (2005): Small and medium enterprises (SMES) in Nigeria: problems and prospects;

3. Busani Moyo (2012): Do power cuts affect Productivity? A case study of Nigerian manufacturing Firms; International Business and Economics Research Journal.

4. Carlos Pestana Barros Et al (2011) Nigeria Power Sector: Analysis of Productivity

5. Akiri, E.L (2015) Electricity supply and the manufacturing productivity in Nigeria; IOSR Journal of Economics and Finance, Volume 6 PP 90-94

6. Mba Okechukwu Agwu and Dr Cletus Izunwanne Emeti (2014) Issues, Challenges and Prospects of small and medium scale enterprises (SMEs) in Port-Harcourt city, Nigeria; European Journal of sustainable development.

7. Emmanuel Noko (2016): Impact of power supply failure in Nigeria economy 1981 - 2015; EduCacInfo.com

8. European journal of business and social sciences volume 2 No 9 page 76 -94 (2013) SMES Business risks and sustainable in Nigeria.

9. Gbadebo, Olusegun Odularu and Chinedu Okonkwo (July 2009) Does energy consumption contribute to economic performance? Empirical evidence from Nigeria Journal of Economics and International Finance Vol. 1(2), pp. 044-058

10. Harnessing the Potentials of the Informal Sector for Sustainable Development - Lessons from Nigeria Joseph O. Dada

11. Ekpo, I A H and Umoh, O J. (2013): The informal sector; an overview of Nigerian growth and development posted by web 29/12/2013

12. Iduu Gloria (2012) Power supply and the performance of small and medium scale industries in Nigeria $(1986$ - 2012)

13. Ismail O. Fasanya and Adegbemi B.O Onakoya (2012) Informal sector and employment generation in Nigeria; Research on humanities and social sciences Vol 2, No.7.

14. Jonathan Emenike Ogbuabor and Victor A. Malaolu (2013) Size and Causes of the Informal Sector of the Nigerian Economy: Evidence from Error Correction Mimic model; Journal of Economics and Sustainable Development www.ïste.orgVol.4, No.1 
15. KPMG in Nigeria (2016) A guide to the Nigeria power sector.

16. Mbunwe and Muncho Josephine (2014) Analysis of Energy Crisis and How it Affects Production Sector and Economic Growth of Nigeria; Proceedings of the World Congress on Engineering and Computer Science Vol I, 22-24 San Francisco, USA

17. Nwankwo Olivia Chigozie and Njogo, Bibiana Oluchukwu (2013) The Effect of Electricity Supply on Industrial Production within the Nigerian Economy (1970 - 2010); A Journal of Energy Technologies and Policy www.iiste.org Vol.3, No.4.

18. Ogaji Comfort- Asokoro (2011): The importance of energy to the Nigerian economy.

19. Onyemaechi Joseph Onuwe (2013) Role of Informal Sector in development of Nigeria economy; output and employment approach; NOUN A journal of economics and development studies

20. Peter Samuel Ubi Et al (2012) An Econometric Analysis of the Determinants of Electricity Supply in Nigeria; International Journal of Business Administration Vol. 3, No. 4.

21. Tajudeen Olalekan Yusuf and Francis Sewhenu Dansu(2013) SMEs, Business risks and sustainability in Nigeria; European Journal of Business and Social Sciences, Volume 2 No 9 PP 76-94

22. The Nigeria of experience international conference on Arts, Economics and Management (2014): The role of small and medium enterprises in economic development.

23. The Sun Newspaper (28 ${ }^{\text {th }}$ March 2016) How Epileptic Power Supply's killing Nigerian Industries.

24. Udochukwu B Akuru and Ogbonnaya I Okoro (2014) Economic Implications of Constant Power Outages on SMEs in Nigeria; Journal of Energy in Southern Africa Volume 25

25. Ugochukwu .U. Ikeije Et al (2016) Labour practices in the informal sector of Nigerian economy; Global Journal of Arts, Humanities and Social Sciences; Vol.4, No.2, pp. 6-14

26. Yusuf Olabisi Sherifat Et al Factors affecting small scale business performance in informal economy in Lagos state: A gendered based analysis

27. Yusuf Olabisi Sherifat (2011) A theoretical Analysis of the concept of informal economy and informality in developing countries; European journal of social sciences- volume $20 \mathrm{No} 4$ 